\title{
NI Dental Practice Committee elects Ciara Gallagher as Chair
}

\footnotetext{
The Northern Ireland Dental Practice Committee

(NI DPC) has

elected Ciara

Gallagher as

chair at its first

meeting for the

new triennium

2022-2025. Philip

McLorinan and

Helen Brogan were elected vice chairs.

The next three years will

be crucial for the survival of health service

dentistry in Northern Ireland,' said Ciara. 'NI

DPC has both challenges and opportunities

ahead, as we embark on negotiations for

a new health service contract for general

dental services for our population.

'The last few years have been particularly difficult for dentists and dentistry
}

in Northern Ireland, navigating the unprecedented challenges of the pandemic, while also managing the ongoing, dayto-day clinical and practical elements of running a dental practice.

'I am conscious that I take up the reins from a worthy predecessor in Richard Graham, who steered the Committee through the worst of COVID-19.

'With the full force and support of the Committee behind me, I am looking forward to leading health service dentistry into a new era, negotiating a new contract with the Department of Health, ensuring that we have a financially viable, affordable, secure, sustainable and safe future for health service dentistry in Northern Ireland.'

Ciara brings over 25 years' experience to the role of NI DPC chair. She qualified as a dentist from the University of Birmingham in 1996, working in Nottingham and Birmingham for two years before coming home to Northern Ireland.

She is now the sole owner of a seven surgery dental practice in Downpatrick, where family NHS dentistry and high quality private implant and cosmetic dentistry sit comfortably side by side. Having worked in NHS dentistry for more than two decades, Ciara has felt first-hand the rising pressures of providing quality NHS care under an increasingly pinched budget.

She is a passionate believer that everyone should have access to quality dental care regardless of ability to pay. As chair, Ciara welcomes the opportunity for NI DPC to work closely and collaboratively with the Department of Health to formulate a new contract which works for patients, dentists and the government.

\section{Higher examination fees will do little to address the backlog of unmet patient care}

The British Dental Association Scotland has said the higher fees for examination will do little to address the colossal backlog of unmet patient care that has accumulated during the pandemic.

While apparently a positive move on the face of it, the reality is that many dentists will have very limited capacity to increase examinations as they already have an enormous number of patients awaiting treatment. Colleagues have reported that they continue to focus on urgent treatment and that it will be several months before

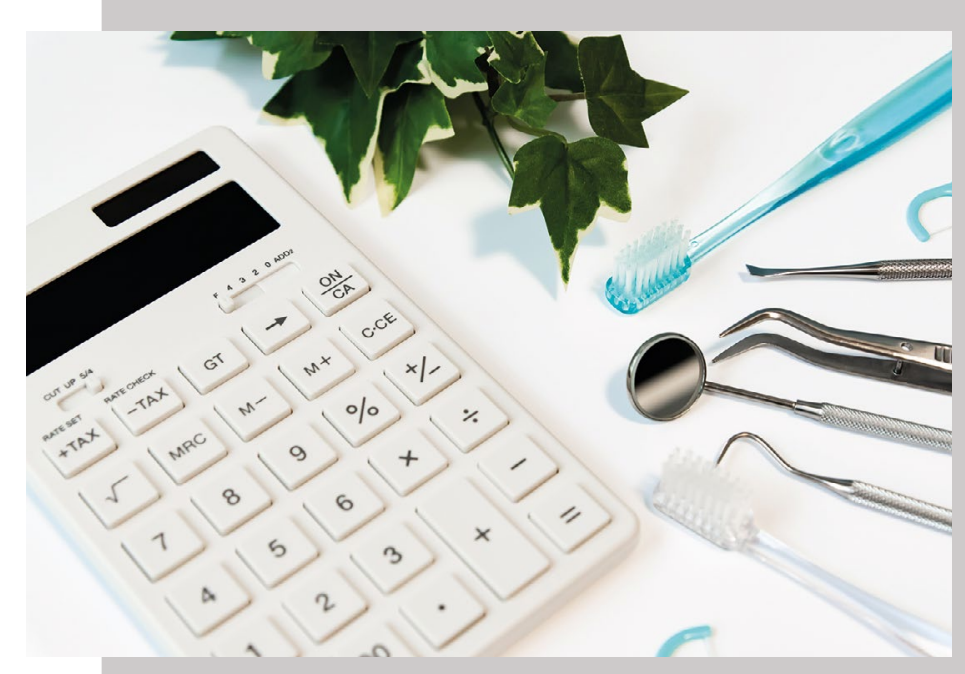

they can see patients for routine treatment. With high COVID-19 transmission rates, continued restrictions in how dental practices operate, and many staff selfisolating, dentists are a long way from returning to 'business as usual'.

These examinations will also require additional time (especially where a full periodontal charting is needed) which will negate the higher fees. This demonstrates a lack of understanding of how dental practices operate. The BDA's Scottish Dental Practice Committee have continually asked for the methodology Scottish Government uses to determine fees. The new examination fees will purchase around eight minutes of clinical time from when the patient enters the practice until they leave; if the consultation exceeds 8 minutes, practices will incur a financial loss. The BDA has repeatedly stressed that the Government needs to discuss proposals at an early stage and to take account of dentists' feedback.

Despite the Scottish Government's claims, it is not clear how the new fees will help to tackle inequalities. While BDA Scotland welcomes the extension of fluoride varnish applications (from 2-5 year-olds to 2-12 year-olds) - which the BDA had previously called for - and the Government's recent announcement of additional resources for children's oral health, frontline dentists have advised that the expansion of the Childsmile programme to include older children may not be practical in dental settings.

David McColl of the BDA's Scottish Dental Practice Committee said: 'The new examination fees barely scratch the surface of massive underfunding. They are well short of the $£ 37$ examination fees paid to optometrists and do nothing to compensate for the woefully low fees elsewhere in the SDR.

'The Scottish Government needs to significantly increase these fees as part of an interim funding model to ensure NHS dentistry remains viable for dentists and our patients.' 